RUNNING HEAD: ATTENDING TO THE CHEMICAL SENSES

\title{
Attending to the chemical senses
}

Prof. Charles Spence,

Crossmodal Research Laboratory, Oxford University

RESUBMITTED TO: Multisensory Research

WORD COUNT: 13,600 WORDS

DATE: June 15th, 2019

CORRESPONDENCE TO: Prof. Charles Spence, Department of Experimental Psychology, Anna Watts Building, University of Oxford, Oxford, OX2 6GG, UK. E-mail: charles.spence@psy.ox.ac.uk 


\begin{abstract}
Theorizing around the topic of attention and its role in human information processing largely emerged out of research on the so-called spatial senses: Vision, audition, and to a lesser extent, touch. Thus far, the chemical senses have received far less research interest (or should that be attention) from those experimental psychologists and cognitive neuroscientists interested in the topic. Nevertheless, this review highlights the key role that attentional selection also plays in chemosensory information processing and awareness. Indeed, many of the same theoretical approaches/experimental paradigms that were originally developed in the context of the spatial senses, can be (and in some cases already have been) extended to provide a useful framework for thinking about the perception of taste/flavour. Furthermore, a number of those creative individuals interested in modifying the perception of taste/flavour by manipulating productextrinsic cues (such as, for example, music in the case of sonic seasoning) are increasingly looking to attentional accounts in order to help explain the empirical phenomena that they are starting to uncover. However, separate from its role in explaining sonic seasoning, gaining a better understanding of the role of attentional distraction in modulating our eating/drinking behaviours really ought to be a topic of growing societal concern. This is because distracted diners (e.g., those who eat while watching TV, fiddling with a mobile device or smartphone, or even while driving) consume significantly more than those who mindfully pay attention to the sensations associated with eating and drinking.
\end{abstract}

KEYWORDS: ATTENTION; CHEMICAL SENSES; FLAVOUR; TASTE; SMELL. 


\section{Introduction}

Researchers have been talking about attention since the end of the $19^{\text {th }}$ century (e.g., James, 1890; Titchener, 1908, for a couple of famous early examples). However, it was only really in the middle of the $20^{\text {th }}$ century that attention research really started to take off in earnest amongst cognitive psychologists trying desperately to understand, and then to alleviate, the problems faced by $2^{\text {nd }}$ World War pilots (e.g., Styles, 2006). The latter often failing to simultaneously monitor multiple auditory channels of communication effectively, hence explaining the early focus of attention researchers on the dichotic listening situation (see Driver, 2001, for a review). With the emergence of the personal computer, the focus of attention research largely shifted away from the auditory to the visual modality (e.g., LaBerge, 1995; Posner, 1978; though see Spence \& Driver, 1994, for an exception). Thereafter, researchers slowly started to turn (their attention) toward investigating any crossmodal links in attention, initially focusing on the auditory and visual modalities, and thereafter incorporating touch (and, indirectly, proprioception into their reasoning/experimentation; see Spence \& Driver, 2004, for a review).

It is only recently that researchers have really started to consider in earnest the role that attention might play in olfactory and gustatory information processing (e.g., Ashkenazi \& Marks, 2004; Marks, 2002; Marks, Elgart, Burger, \& Chakwin, 2007; Marks \& Wheeler, 1998; Spence, 2014; Veldhuizen \& Small, 2011), as well as in multisensory flavour perception (Stevenson, 2012). This is, in one sense at least, surprising, given the profoundly complex multisensory flavour experiences that many foods and drinks deliver (though see Spence \& Wang, 2018, on the varied meanings of complexity as far as the chemical senses are concerned). Titchener, one of the godfathers of the field of experimental psychology, hints at this when he writes: "Think, for instance, of the flavour of a ripe peach. The ethereal odor may be ruled out by holding the nose. The taste components-sweet, bitter, sour-may be identified by special direction of the attention upon them. The touch components-the softness and stringiness of the pulp, the pucker feel of the sour-may be singled out in the same way. Nevertheless, all these factors blend together so intimately that it is hard to give up one's belief in a peculiar and unanalyzable peach flavour. Indeed, some psychologists assert that this resultant flavour exists." (Titchener, 1909, p. 135; see also Masumoto, 2003). Titchener here articulating the role of attention both in singling out particular features in a complex multisensory tasting experience, as well as in helping to bind those various unimodal features together into so-called 'flavour objects' (Stevenson, 2009). Indeed, at the outset, it should be noted that flavour perception constitutes an especially complex example of the temporally- 
evolving integration of multiple sensory cues into a coherent perceptual experience (Auvray \& Spence, 2008; Bult, de Wijk, \& Hummel, 2007; Prescott, 2004; Small, 2012; Spence, 2015b; Spence, Smith, \& Auvray, 2015).

The importance of food and, in particular, food-related sensory cues, to the human brain is hinted at by the observation that there is nothing that leads to as great an increase in cerebral blood flow as the sight of our favourite foods while we are hungry (Wang, Volkow, Telang, Jayne, Ma, Rao, Zhu, Wong, Pappas, Geliebter, et al, 2004) (see Figure 1). This is a

particularly striking result given the fact that the brain is by far the body's most blood-thirsty organ, consuming c. $25 \%$ of total energy (e.g., Allen 2012; Wrangham 2010). That said, it aligns with the following quote from the eminent British biologist J. Z. Young from half a century ago when he stated that: "No animal can live without food. Let us then pursue the corollary of this: Namely, food is about the most important influence in determining the organization of the brain and the behavior that the brain organization dictates. " (Young, 1968, p. 21). Young here stressing the role of food in brain evolution. In the same conference proceedings paper, Young also draws his readers' attention to the fact that in pretty much every species, the brain tends to be located close to the mouth (or first point of entry of foods into the organism). Meanwhile, as Allman (2012, p. 111) notes, the first part of the neocortex to develop in embryos goes on to become the representation of the tongue and mouth in the somatosensory and motor cortex, and this is, presumably, also no coincidence. As Allman puts it: "The neocortex then develops in concentric zones extending out from this core region." In short, food is key both to brain development and the deployment of attention.

\section{INSERT FIGURE 1 ABOUT HERE}

\section{Hunger and its impact on the processing of food-related sensory cues}

Food, food cues, and hunger, while largely being neglected by cognitive psychologists and cognitive neuroscientists interested in attention have, in recent years, been shown to profoundly influence multisensory information processing in humans. Furthermore, a number of the key concepts/approaches that have emerged from the study of attention in the higher spatial senses (e.g., of vision, audition, and touch), appear to apply just as well when it comes to a consideration of the chemical senses (focusing here specifically on the senses of olfaction and 
gustation). ${ }^{1}$ In fact, an emerging body of empirical research now shows that our brain's rapidly process visual information in order to assess the energy-density (or fat content) of anything edible in the scene and then pays (visual) attention accordingly (e.g., Harrar, Toepel, Murray, \& Spence, 2011; Sawada, Sato, Toichi, \& Fushiki, 2017; Toepel, Knebel, Hudry, Lecoutre, \& Murray, 2009). Furthermore, and perhaps unsurprisingly, the hunger state of an individual has also been shown to modulate the attention-capturing potential of various food-related visual cues (e.g., see Brignell, Griffiths, Bradley, \& Mogg, 2009; Channon \& Hayward, 1990; Lavy \& van den Hout, 1993; Loeber, Grosshans, Herpertz, Kiefer, \& Herpertz, 2013; Mogg, Bradley, Hyare, \& Lee, 1998; Ohla, Toepel, le Coutre, \& Hudry, 2012; Piech, Pastorino, \& Zald, 2010; Radel \& Clément-Guillotin, 2012; see also Grabenhorst, Rolls, \& Margot, 2011). The researchers in many of these studies typically contrasting hungry with sated within the same participants; Note here that there is also evidence to suggest a chronic biasing of visual attention toward food-related cues in those individuals who are obese (e.g., Castellanos, Charboneau, Dietrich, Park, Bradley, Mogg, et al., 2009; Nijs, Muris, Euser, \& Franken, 2010).

A large body of empirical research, both behavioural and psychophysical, now shows that attention tends to be drawn toward, or at least there is preferential processing of, those visual stimuli that somehow relate to food in hungry participants (e.g., Fadardi \& Bazzaz, 2011; Radel \& Clément-Guillotin, 2012; Weng, Lin, Ma, Peng, Hu, Zhou, Shen, Wang, \& Wang, 2019). For instance, in one small between-participants study ( $\mathrm{N}=42$ participants), Radel and ClémentGuillotin (2012) demonstrated enhanced perceptual sensitivity for the detection of 20 nearthreshold masked food-related words (such as 'bread' and 'cake') in hungry (that is, fasting) as compared to satiated participants. The participants in the hungry group in this study had gone 3-4 hrs without eating. By contrast, no such benefit was documented for 60 neutral words, such as 'boat' and 'glove'.

Elsewhere, meanwhile, Chinese researchers have demonstrated that food images tend to dominate for significantly longer than non-food images under conditions of perceptual rivalry in those participants who are hungry as compared to the same individuals when sated (Weng et al., 2019). The students in the latter study were shown pairs of images, one food-related, the other neutral (such as, for example, a picture of a clock; see Figure 2), under conditions of

\footnotetext{
1 That said, one also finds some, like Stevenson and Attuquayefilo (2013), arguing that olfactory attention/information processing may be special, and in important ways different from attention in the spatial senses. As they put it: "More generally, we conclude that certain particular features of olfactory cognition may owe more to limited neocortical processing resources, than they do to the challenges faced by perceiving chemical stimuli." (Stevenson \& Attuquayefilo, 2013, p. 1),
} 
binocular rivalry. The food-related images dominated (that is, they suppressed awareness of the non-food image) for longer when the participants were tested before lunch/dinner than when tested after the meal. By contrast, satiation had no such effect on dominance durations for the non-food images. In a follow-up experiment, these researchers went on to demonstrate that probe reaction times, involving the detection of one of the rivalrous images being altered, were shorter for those targets relating to the food image than the non-food image (thus providing evidence against a response bias interpretation of their results). In this particular study, the participants were given a meal of 3,134 kilojoules (or approximately 750 calories). That said, no effect of image type was documented in another experiment involving the continuous flash suppression paradigm. There is a separate literature documenting the impact of the consumption of food/sugar on cognitive processing (e.g., Giles, Avanzato, Mora, Jurdak, \& Kanarek, 2018; Ginieis, Franz, Oey, \& Peng, 2018; Wolraich, Wilson, \& White, 1995). However, while Giles et al. recently reported that the consumption of sugar led to an enhancement in performance in those tasks requiring sustained attention, Ginieis et al. reported that the consumption of sugar and glucose actually led to impaired cognitive performance in an attention-demanding task instead. Schreiber and White (2013) have also highlighted the importance of satiety and relevance to crossmodal attention.

\section{INSERT FIGURE 2 ABOUT HERE}

According to early work by Gilchrist and Nesberg (1952), food-related images are perceived as brighter by hungry participants. Intriguingly, however, hunger has not only been shown to modify the salience of food-related visual cues, but also the interpretation of ambiguous visual stimuli (e.g., Lazarus, Yousem, \& Arenberg, 1953; see also Changizi \& Hall, 2001). ${ }^{2}$ Research conducted over the last decade or so has started to uncover a number of the neural mechanisms by which hunger modulates the attentional capture by visual food cues (e.g., see Bielser, Crézé, Murray, \& Toepel, 2016; Chen, Papies, \& Barsalou, 2016; LaBar, Gitelman, Parrish, Kim, Nobre, \& Mesulam, 2001; Siep, Roefs, Roebroeck, Havermans, Bonte, \& Jansen, 2009; Stockburger, Schmälzle, Flaisch, Bublatzky, \& Schupp, 2009).

On the basis of an evolutionary psychology analysis, Al-Shawaf (2016) raised the possibility that hunger might well be expected to help improve people's ability to detect food-related

\footnotetext{
${ }^{2}$ Early on, Bruner and Goodman (1947, p. 33) stressed the importance of studying the possibility that hunger might influence perceptual mechanisms in order to solve the adaptive problem of finding food, stating that: "What we must study ... are the variations perception itself undergoes when one is hungry, in love, in pain, or solving a problem".
} 
sounds and smells (and not just food-related visual stimuli). ${ }^{3}$ Indeed, olfactory detection thresholds have been reported to differ significantly when participants are tested in the hungry as compared to sated state (Albrecht, Schreder, Kleemann, Schöpf, Kopietz, Anzinger, Demmel, Linn, Kettenmann, \& Wiesmann, 2009; see also Bragulat, Dzemidzic, Bruno, Cox, Talavage, Considine, et al., 2010; Duclaux, Feisthauer, \& Cabanac, 1973). That said, though, and counter to what one might have predicted, Albrecht et al. found that the threshold for detecting the food odour amyl acetate actually increased when participants were hungry. They also reported that the food odour was rated as smelling more pleasant in the hungry state. No such changes were reported for a non-food odour (n-butanol). By contrast, Zverev (2004) has documented the expected reduction in taste thresholds for sucrose and salt (but not bitter) after fasting when compared to threshold performance following caloric loading.

\section{$\underline{\text { Attention and flavour binding }}$}

Tasting something like Titchener's (1908) peach, or perhaps even more impressively, one of the delectable dishes served at Denis Martin's two Michelin-starred Swiss restaurant (see Figure 3) confronts the taster with a multitude of flavour sensations. The latter dish, from Martin's namesake restaurant in Vevey, Switzerland, is served on a spoon. Crucially, in a single mouthful, the attentive diner gets to experience an ordered sequence of distinctive flavours/mouthfeels, each revealing themselves one after the other. In my own case, the first experience was the sharp trigeminal 'hit' of the wasabi. This was followed by the tender oily flavour/texture of the tuna itself. Finally, there was the slow creamy melting mouthfeel of the white chocolate. Part of the pleasure of this dish was the very temporal evolution of the distinctive mouthfeel/flavour experiences, a sequence of distinct sensations that has been deliberately designed by the chef. Had the various ingredients simply been mixed together, the ensuing unitary flavour experience would likely have been quite different, not to mention less pleasurable (see Spence, Wang, \& Youssef, 2017).

\section{INSERT FIGURE 3 ABOUT HERE}

In order to fully enjoy the progression of this dish, the taster presumably has to attend to what is going on in their mouth/nose in order to bind the relevant sensory features into a temporal

\footnotetext{
${ }^{3}$ Here, it is perhaps worth noting that product-related food and beverage sounds have been shown to bias both overt and covert visual attention in an online product search task (Knoeferle, Knoeferle, Velasco, \& Spence, 2016).
} 
sequence of flavour objects (Stevenson, 2009). At the same time, however, the taster's attention is presumably also needed to help ensure the correct segregation of the various flavour cues belonging to the different components in the dish. Otherwise, there would presumably be the possibility of illusory conjunctions in the world of taste/flavour akin to those discussed in the case of vision (Cohen \& Ivry, 1989; Spence \& Frings, in press; Treisman \& Schmidt, 1982; cf. Cinel, Humphreys, \& Poli, 2002). The tasting experience would presumably have been very different had the trigeminal hit of the wasabi been inappropriately bound in the tasting experience with the lingering creamy sensation associated with the melting white chocolate.

Anecdotally, adding a crispy element to a smooth bacon and egg ice-cream appears to lead to a segregation of the bacon flavour from the eggy notes in the texturally appropriate crispy substrate (see Spence \& Piqueras-Fiszman, 2016). Should such informal observations be backed up by the results of carefully-controlled psychophysical research, then it would perhaps support the notion that Bayesian priors (in Bayesian decision theory) may well act to constrain the likely combination of unisensory cues in multisensory flavour perception much as they have been shown to do elsewhere in the world of multisensory perception (e.g., Ernst, 2012; Ernst \& Bülthoff, 2004).

While a few researchers, notably Stevenson (2012, 2014a, 2016), have written about flavour binding, it is worth stressing here that there is a notable absence of research on this topic, at least considering Treisman's hugely influential feature integration theory (Treisman \& Gelade, 1980) when it comes to the binding of the various sensory cues contributing to flavour perception (Spence \& Frings, in press). Perhaps the closest one gets being Delwiche, Lera, and Breslin's (2000) gustatory search study involving the search through multiple tasty jelly cubes to find the one cube in the participant's mouth that had no taste. Taken together, therefore, further research is undoubtedly still needed if we are to gain a better sense of the extent to which the same principals of attentional feature binding that have been established in the spatial senses also extend to the binding of flavour cues in the chemical senses

\section{Perceptual load}

Perceptual load has been a popular notion/framework in selective attention research in recent years. According to this particular attempt to resolve the sometimes confusing literature around the early/late debate (in attentional selection), the suggestion is that at any moment, information processing resources continue to be used until they have been exhausted (e.g., see Lavie, 1995, 
2005; though see also Navon, 1984; Tsal \& Benoni, 2010, 2013, for a critical account). Hence, in the typical distractor (or flanker) interference task that has been conducted in vision, increasing the perceptual load of a primary task reduces the extent to which other (possibly task-irrelevant) stimuli may be processed (see Murphy, Spence, \& Dalton, 2017b, for a review of research on auditory load). That said, researchers have struggled to come to any satisfactory consensus as to whether or not perceptual load should be thought of in terms of a modalityspecific construct, versus each sensory modality having its own pool of attentional resources (see Franceroni, 2013; Macdonald \& Lavie, 2011; Wahn, Murali, Sinnett, \& König, 2017; and Murphy, Dalton, \& Spence, 2017a, for a review). And, beyond that, of course, it isn't even clear what exactly resources are, beyond a sometimes useful theoretical framework (e.g., see Benoni \& Tsal, 2010, 2013; Tsal \& Benoni, 2010, for a critical assessment; and Lennie, 2003).

Nevertheless, despite the uncertainty, the general approach, of manipulating task-load, has now been applied to the world of the chemical senses (e.g., Forster \& Spence, 2018; Van der Wal \& van Dillen, 2013). So, for example, in the four studies reported by Van der Wal and van Dillen, ratings of the intensity of the taste of sweet, salty, and sour-tasting substances were lower (that is, the taste solutions were rated as less intense) under conditions of high working memory load. The participants in this particular series of studies were either required to remember a random list of 7 digits/letters (high-load), or else just to remember a single digit/letter (low load). What is more, when asked to mix a drink to taste, more of the sweet tastant was added under conditions of high working memory load than in the low-load condition. In one experiment, the participants were invited to taste a buttered cracker in order to rate its saltiness (the butter spread was either salted or unsalted). Those in the high load condition consumed significantly more of the cracker than those in the low load condition.

Meanwhile, across three experiments, Forster and Spence (2018) demonstrated that performing a high load visual search task (in which the in which the target, either an " $\mathrm{X}$ " or an " $\mathrm{N}$ ", was presented amongst five heterogenous yet similar-looking angular distractor letters) resulted in inattentional anosmia for a food-related odour of freshly-ground coffee. The ambient aroma was significantly more perceptible in a low-load condition, where the target letter was presented-amongst five place holders (letter 'o's). In Forster and Spence's first two experiments, $42.5 \%$ fewer participants were aware of the ambient coffee aroma in the highload condition than in the low-load condition. These results certainly fit with Sela and Sobel's (2010) suggestion from a few years ago that olfaction is in a constant state of change blindness. Taken together, therefore, the results of load-based manipulations of processing resources 
would appear to suggest that people's perception in the chemical senses is subject to the same influences of loading perceptual, or working memory, resources as have been documented in a number of other studies conducted over the last quarter of a century or so.

\section{Sensory dominance}

Visual dominance (often considered to be an attentional phenomenon, e.g., see Posner, Nissen, $\&$ Klein, 1976) has been argued to be part of the explanation for why it is that visual cues (such as the colour of a drink) bias people's interpretation of the identity/intensity of taste/ flavour (see Spence, 2015c, for a review). While several hundred published studies have now documented the influence of colour on taste/flavour ratings, people do sometimes want to know whether similar kinds of sensory dominance effect also operate in the reverse direction. Or, in other words, does (or can) what we taste/smell capture and/or change, what we see? The most relevant evidence on the latter question, comes from research showing that olfactory cues can be used to draw people's visual attention to the congruent, or related, stimuli in a visual scene (e.g., see Chen, Zhou, Chen, He, \& Zhou, 2013; Seigneuric, Durand, Jiang, Baudouin, \& Schaal, 2010; Seo, Roidl, Müller, \& Negoias, 2010; see also Allen \& Schwartz, 1940, for early work on this topic). So, for example, both Seigneuric et al. and Seo et al. reported that olfactory stimuli tend to bias free-viewing behaviour (i.e., overt visual attention), such that participants are more likely to look at the object that is linked to (or associated with) the smell than they are when the odour is absent. ${ }^{4}$ Meanwhile, a series of experiments by Chen et al. demonstrated that olfactory stimuli (such as the smell of rose, citral/lemon, and a banana-like odour) influenced participants' performance in two traditional attentional paradigms, namely the dotprobe and visual search tasks. In particular, presenting the various olfactory cues was shown to direct participants' visual attention to the congruent visual stimuli, and by so doing significantly facilitate their behavioural performance. What is more, these exogenous crossmodal effects were powerful enough to override any top-down (or endogenous) attentional effects, when the identity of the olfactory cue was made counterpredictive with respect to the identity of the visual target.

\footnotetext{
${ }^{4}$ Many published studies have shown that people's ratings of visual images of faces can be biased by the presence of specific odorants (e.g., see Demattè, Österbauer, \& Spence, 2007; Li, Moallem, Paller, \& Gottfried, 2007, for a couple of representative studies in this area). However, it is a little less clear that attention has any specific role to play in explaining the latter results.
} 
Despite the fact that several of the just-mentioned findings (see Chen et al., 2013; Seigneuric et al., 2010; Seo et al., 2010) can be described in terms of crossmodal links in attention (i.e., when olfactory cues lead to attentional capture by the associated visual stimuli), it is important to note that the notion of crossmodal links in explicitly spatial attention does not translate so easily into the chemical senses. Indeed, the latter effects are not inherently spatial, inasmuch as it is not the perceived location of the source of scent that draws a participant's attention to its location, but rather to the location of visual stimuli that happens to be associated with that scent. And while we can to a certain extent localize gustatory and olfactory stimuli, they are by no means really spatial senses, at least not in the way that audition, vision, and touch are thought to be. This despite the fact that the latest evidence suggests that people can localize (or at the very least lateralize) olfactory cues much better than was previously thought (Porter, Craven, Khan, Chang, Kang, Judkewitz, Volpe, Settles, \& Sobel, 2007). ${ }^{5}$

Researchers working in the spatial senses often distinguish between overt and covert orienting of attention (see Spence, 2014, for a review), with eye, head, and other bodily movements being taken as the overt signs of a shift of a person's attention. The majority of attention research that has been published to date has tended to focus on the covert shifts (i.e., internal changes) in attention that occur as a result of focusing on one stimulus, location, or feature over others (e.g., see Jensen, Merz, Spence, \& Frings, 2019). One might, therefore, legitimately wonder whether a similar distinction between overt and covert orienting also applies in the case of the chemical senses. Salivation (see Spence, 2011, for a review of multisensory influences on salivation) has been put forward as an overt indicator of, or marker for, gustatory attention (see Spence, 2014). Meanwhile, inhaling / sniffing, otherwise referred to as orthonasal olfaction (e.g., Rozin, 1982; see also Bojanowski \& Hummel, 2012), has also been observed in those who are even just imagining the smell of something (see Bensafi, Porter, Pouliot, Mainland, Johnson, Zelano, et al., 2003; Krishna, Morrin, \& Sayin, 2014; Stevenson \& Case, 2001; Wachowiak, 2011).

Separately, there is certainly plenty of evidence to suggest that the presence of gustatory and/or olfactory cues can enhance the sense of immersion in virtual reality (see Hoffman, Hollander, Schroder, Rousseau, \& Furness, 1998; see also Ischer, Baron, Mermoud, Cayeux, Porcherot, Sander, \& Delplanque, 2014; Jones, Bowers, Washburn, Cortes, \& Satya, 2004; Ranasinghe,

\footnotetext{
5 McGann (2017) has argued persuasively for the role of early interest in the pre-frontal cortex displacing consideration of olfactory function.
} 
Cheok, Nakatsu, \& Do, 2013). In fact, several research groups have also reported how the delivery of task-irrelevant alerting olfactory cues, such as peppermint and citrus aroma, can enhance visual attention via scent's ability to alert participants (e.g., Ho \& Spence, 2005; Ilmberger, Heuberger, Mahrhofer, Dessovic, Kowarik, \& Buchbauer, 2001; Michael, Jacquot, Millot, \& Brand, 2003, 2005; Warm, Dember, \& Parasuraman, 1991). Beyond that, a couple of studies have also shown that olfactory cues can be used to bias people's visual attention under conditions of binocular rivalry (e.g., Zhou, Chen, Wang, \& Chen, 2012; Zhou, Jiang, He, $\&$ Chen, 2010). Taken together, such results would appear to support the view that crossmodal interactions do indeed operate in both directions - and while the majority of research to date has tended to focus on vision's role in setting taste/flavour expectations, what we taste and smell exerts a not inconsiderable influence over what we experience visually, at least under a certain subset of conditions. Furthermore, researchers have also started to get a better sense of the neural substrates underlying such bidirectional crossmodal influences (see Thesen, Vibell, Calvert, \& Österbauer, 2004).

\section{Attending to the chemical senses}

\section{Endogenously attending to chemosensory stimuli}

Researchers have used probability/instructional manipulations in order to try and direct (or focus) a participant's endogenous attention on the chemical senses (e.g., Ashkenazi \& Marks, 2004; Marks \& Wheeler, 1998; Veldhuizen \& Small, 2011). For instance, Marks and Wheeler demonstrated that detection thresholds assessed in a 2-alternative forced-choice (2AFC) experiment for a particular tastant (e.g., sucrose) were selectively lowered when their participants $(\mathrm{N}=6)$ directed their attention endogenously toward that stimulus, relative to when they were directed to expect another stimulant (e.g., citric acid) instead. A 75-25\% probability manipulation for the attended (vs. the unattended) stimulus was also incorporated into the experimental design in order to give participants a reason to follow the experimenter's verbal instructions. Crucially, the results revealed that taste thresholds were around $0.2 \log$ units smaller (that is, sensitivity was slightly, but significantly, greater) for each of the tastants when it was attended as compared to when it was not.

Meanwhile, in a series of early studies, my colleagues and I adapted the paradigm for eliciting endogenous shifts of attention to a particular sensory modality that had been developed while studying the spatial senses (see Spence, Nicholls, \& Driver, 2001) in order to study the role of 
attention in chemosensory information processing (Spence, Kettenmann, Kobal, \& McGlone, 2000, 2001a, b). In particular, using such an approach, we were able to demonstrate that attending endogenously to olfaction resulted in attentional facilitation of reaction times in an orthogonal speeded discrimination task. The probability with which olfactory or visual targets appeared was varied over successive blocks of experimental trials. This probability manipulation was paired with task instructions highlighting the need to attend to the more likely target modality. The task in this case was orthogonal in the sense that the participants were instructed to direct their attention to either the olfactory or visual modality, while making speeded discrimination responses regarding the side on which (specifically, the left vs. right nostril) or intensity (weak vs. strong) of the target, be it olfactory or visual, was presented. The attentional manipulations in Spence et al.'s studies giving rise to RT effects (costs and benefits) for the processing of olfactory/trigeminal targets that were not too dissimilar in magnitude from those seen for targets presented in the spatial modalities.

Attending (either overtly or covertly) to the chemical senses not only allows an individual to respond to the presence of chemosensory stimuli more rapidly/accurately than if their attention happens to be directed elsewere (Spence et al., 2000, 2001a, b; see also Aarts, Dijksterhuis, \& De Vries, 2001) but it also enables the observer/taster to make enhanced discrimination responses to the various components in odour mixtures, such as hinted at by Titchener in the quote that appeared at the start of this piece (e.g., Jinks \& Laing, 1999; Laing \& Glenmarec, 1987; Rabin \& Cain, 1989). A similar modest ability to direct attention to the components of taste mixtures has also been reported (Kuznicki, Hayward, \& Schultz, 1983; Kuznicki, \& Turner, 1986). In fact, one can perhaps frame the instructions that have been delivered in a number of the well-publicized neuroimaging studies that a particular taste stimulus is going to be 'very bitter' or 'very sweet', say, as effectively directing a taster's endogenous attention to something particular in their tasting experience (cf. Lacey \& Lawson, 2013; Segal \& Fusella, 1970, 1971; Stevenson \& Case, 2005, on the role of mental imagery in facilitating, or interacting with, perception in the chemical senses). After all, there is neuroimaging evidence to suggest that visual cortex is recruited in those who find themselves in the tip-of-the-nose state (see Qureshy, Kawashima, Imran, Sugiura, Goto, Okada, et al., 2000).

Elsewhere, however, when Ashkenazi and Marks (2004) investigated the role of attention in the detection of weak olfactory and gustatory flavours, the story starts to become much more complicated. One again, a 2AFC method was used to assess whether participants could attend selectively to either the gustatory or the olfactory component of sucrose-vanillin mixtures. 
However, the pattern of results that emerged from this study was rather intriguing. In particular, while attending to sucrose was shown to benefit participants' performance when sucrose was presented in isolation, detectability was not improved by attention when sucrose was mixed with vanillin (an odorant). At the same time, however, neither did attending to vanillin improve its detectability when the latter was mixed with sucrose. One suggestion to explain this pattern of results (namely the difficulty of attending to olfactory flavours, or retronasal olfaction) was that the mislocalization of the odorant to the mouth (due to oral referral) may have made it difficult to selectively attend to the component stimuli on the basis of their spatial origin, since both the olfactory and the gustatory stimulus are localized subjectively to the tongue/oral cavity. ${ }^{6}$

Arvisenet Guichard, and Ballester (2016) reported that training/expertise modifies the tastearoma interactions observed in model wines (see also Boakes \& Hemberger, 2012). In particular, wine experts and trained panellists exhibited significantly less sweetness enhancement of the perceived aroma of model wines following the addition of sugar than did non-experts. This result thus suggests an enhanced ability to attend to (or individuate) the various sensory elements contributing to multisensory flavour experiences amongst the more experienced tasters, at least when encouraged to adopt an analytic approach to wine by being presented with separate taste and aroma rating scales. ${ }^{7}$ Elsewhere, Weil (2007) has similarly argued that experts can adopt a more analytic strategy whereas novices tend to respond to wines holistically.

\section{Neural bases for endogenous attention to chemosensory stimuli}

Neuroimaging research by Veldhuizen and Small (2011) clearly highlights the existence of modality-specific neural sites that become more active when attention is selectively directed to taste or to the detection of olfactory stimuli. In particular, primary taste cortex (anterior and mid-dorsal insula) was found to be more active when their participants attended to taste,

\footnotetext{
${ }^{6}$ Separately, there has been some question as to whether flavour might represent a separate modality of perceptual experience (e.g., see Auvray \& Spence, 2008; Gibson, 1966; Stevenson, 2009, 2018b; Veldhuizen, Shephard, Wang, \& Marks, 2010). Indeed, according to one suggestion, it is only possible to direct attention toward flavourful stimuli, but not to the component, or contributing, sensory modalities (at least when they are presented as a taste-odour compound).

${ }^{7}$ At the same time, however, wine experts, at least according to the neuroimaging research, show enhanced integration of the various signals giving rise, or contributing, to flavour percept (Pazart, Comte, Magnin, Millot, $\&$ Moulin, 2014).
} 
whereas the primary olfactory cortex (piriform) was more active when participants directed their attention to olfaction instead. Interestingly, however, there was also an additional focus of activity in another region (far anterior insular cortex) when attention was directed either to taste or to smell. More generally, one of the interesting points to note here concerns the fact that olfaction is the only sense that does not (or rather, does not necesarily) project through the thalamus on its way to the cortex (Keller, 2011; McCormick \& Bal, 1994; Newman, 1995; Plailly, Howard, Gitelman, \& Gottfried, 2008; Portas et al., 1998; Price, 1985; Shepard, 2005; Smythies, 1997; Tham, Stevenson, \& Miller, 2009, 2011). The thalamus is widely considered to be a major site of cortical gating, hence raising the question of the extent to wich attention could be directed toward the olfactory modality. That said, as we have just seen, various researchers have demonstrated attentional modulation in human primary olfactory cortex (Veldhuizen \& Small, 2011; see also Zelano, Bensafi, Porter, Mainland, Johnson, Bremner, Telles, Khan, \& Sobel, 2005). ${ }^{8}$ The latter study reported increased neural activation in frontal piriform cortex and olfactory tubercule in response to attended sniffs when compared to unattended sniffs, no matter whether there was an odorant present or not.

Several studies have demonstrated how the verbal labelling of a tastant can modify the neural activation that is seen in response to tasting a solution in areas as early as primary taste cortex (e.g., Nitschke, Dixon, Sarinopoulos, Short, Cohen, Smith, Kosslyn, Rose, \& Davidson, 2006; Wilton, Stancak, Giesbrecht, Thomas, \& Kirkham, 2018; Woods, Lloyd, Kuenzel, Poliakoff, Dijksterhuis, \& Thomas, 2011; see also Grabenhorst, Rolls, \& Bilderbeck, 2008; though see Spence, 2016b, for a review). Potentially relevant here, simply mentioning a word with strong olfactory associations (such as, for example, 'cinnamon') has been shown to induce activation in olfactory cortex (González, Barros-Loscertales, Pulvermüller, Meseguer, Sanjuán, Belloch, et al., 2006). Researchers have also used neuroimaging in order to investigate individual differences in people's preferences for different alcohol levels in wine (Frost, Quinones, Veldhuizen, Alava, Small, \& Carreiras, 2015).

\section{Exogenous attentional capture by chemosensory stimuli}

\footnotetext{
${ }^{8}$ There is an interesting argument here about the ipsilateral vs. contralateral representation of olfactory stimuli, and the implications of this for spatial representation and attention (see Bellas, Novelly, Eskenazi, \& Wasserstein, 1988).
} 
Separate from any role of instruction in endogenous directing attention to the chemical senses, the suggestion has also been made that noisy foods may be so popular, in part, because they help to draw a taster's attention exogenous to their mouth - i.e., to the spatial source of the sound (see Spence, 2015a, 2017a, on this theme). This attentional focus is thought to enhance the sensations that are experienced when tasting. Along similar lines, some researchers (e.g., Stevenson, Mahmut, \& Oaten, 2011) have also wanted to suggest that it is the focus of a taster's attention to their mouth (rather than their nose) that helps to explain the phenomenon of 'oral referral' (see Spence, 2016a, for a review). ${ }^{9}$ Recent research suggests that gustatory-olfactory congruency does not play a role, nor does the tactile element of tasting, but rather it is the relative saliency, or attention-capturing ability, of the olfactory and gustatory components, at least according to Stevenson et al., that determine whether the combined stimulus will be localized to the nose or, more often, the oral cavity (see Lim \& Green, 2008; see also Lundström, Boesveldt, \& Albrecht, 2011). Meanwhile, Grabenhorst, Rolls, and Margot (2011) have reported that hedonically complex odour mixtures (i.e., those that contain both distinct pleasant and unpleasant components) appear to capture attention particularly effectively (with the relevant neural substrate in this case being localized to the superior frontal gyrus). ${ }^{10}$

It is important to note here the way in which trigeminal irritants, think only of the nasal hit of wasabi, or the oral burn of chilli (see Spence, 2018a, b, for a review) can also very effectively exogenously attract out attention to the bridge of our nose, or oral cavity (Stevenson, 2012). When suitably strong, such trigeminal cues feel like they cannot be easily overridden (Geisler \& Murphy, 2000; Iannilli, DelGratta, Gerber, Romani, \& Hummel, 2008; Labbe, Gilbert, \& Martin, 2008; Silver \& Maruniak, 1981; Stone, Williams, \& Carregal, 1968).

\section{Sonic seasoning: Exogenously drawing attention crossmodally to flavour sensations?}

Some intriguing recent work has adopted sensory science techniques such as the Temporal Dominance of Sensations (TDS) approach, Time-Intensity (TI) analysis (e.g., Wang, Mesz, \&

\footnotetext{
${ }^{9}$ According to one suggestion at least this might be explained in terms of a kind of prior entry for oral over nasal sensations (see von von Békésy, 1963).

${ }^{10}$ In general, bad odours would appear to have more of an impact on speeded responding than either positive or neutral aromas (e.g., Boesveldt, Frasnelli, Gordon, \& Lündstrom, 2010). Meanwhile, according to Baus and Bouchard (2017), it is the unpleasant odours, not the neutral or positive ones, that give rise to increased immersion in virtual reality situations, again, perhaps attributable to unpleasant odours ability to capture people's attention. Note also that people do not adapt to the presence of bad odours in the way they have been shown to adapt to neutral/positive odours (such as the smell of one's own home).
} 
Spence, 2017), and/or Check-All-That-Apply (CATA; e.g., Meyners, Castura, \& Carr, 2013; Oliver, Cicerale, Pang, \& Keast, 2018) in order to help reveal the complex multisensory evolution of sensations that may occur in something as simple as a single mouthful or icecream (e.g., Lin, Hamid, Shepherd, Kantono, \& Spence, 2019; Xu, Hamid, Shepherd, Kantono, \& Spence, in press) or else in a single prolonged mouthful of wine (e.g., see Burzynska, Wang, Spence, \& Bastian, 2019; Wang, Mesz, Riera, Trevisan, Sigman, Guha, \& Spence, 2019). Figure 4 highlights one such example of the average multi-element flavour profile associated with holding a mouthful of wine in the oral cavity for 45 seconds. ${ }^{11}$

\section{INSERT FIGURE 4 ABOUT HERE}

According to recent suggestions, carefully selected auditory stimuli can be used to direct a taster's attention (exogenously) on the basis of the known crossmodal correspondences that have been documented between taste-aroma-flavour and sound (see Deroy, Crisinel, \& Spence, 2013; Knöferle \& Spence, 2012, for reviews). This certainly offers one effective means of modifying people's taste experience (see Spence et al., 2019, for a recent review). Such crossmodal results may fit with the role that attention has been shown to have elsewhere in terms of its ability to enhance stimulus representations (Carrasco, Ling, \& Read, 2004), and crossmodally bias competing stimulus representations/interpretations (e.g., see van Ee, van Boxtel, Parker, \& Alais, 2009). One interesting question here though is the level of information processing at which such sonic seasoning effects (Spence, 2017b) are influencing neural information processing (see Callan, Callan, \& Andon, 2018, for preliminary evidence on this score) Can sonic seasoning, for instance, affect even the earliest neural representations (e.g., biasing the representation of taste quality in the primary taste cortex)? This is another of the areas where further research is needed to clarify the role of exogenous shifts of attention to chemosensory information processing.

\section{$\underline{\text { Attentional distraction and the overconsumption of food }}$}

Beyond the growing academic interest in the role of attention in the processing and perception of information in the chemical senses, there is also a potentially important role as far as understanding, and hence perhaps potentially addressing (in some small way at least), the

\footnotetext{
11 That said, it should be remembered that this figure constitutes an average of data from multiple participants, and hence any individual participant may well only have experienced a subset of the mouth sensations shown.
} 
growing global obesity crisis is concerned (Spence, Reinoso-Carvalho, Velasco, \& Wang, in press). It has frequently been argued that modern technology is directing more of our attentional resources away from the food and drink that we consume than ever before (see Spence, Mancini, \& Huisman, submitted, for a review). This is potentially worrying given the further suggestion that a failure to pay attention to the sensations that are associated with food consumption may itself lead to overconsumption (see van der Wal \& van Dillen, 2013). Common culprits here (in terms of distracting attention) include the TV dinner (e.g., Blass, Anderson, Kirkorian, Pempek, Price, \& Koleini, 2006; Boulos, Vikre, Oppenheimer, Chang, \& Kanarek, 2012; Braude \& Stevenson, 2014; Gore, Foster, DiLillo, Kirk, \& Smith West, 2003), and nowadays increasingly people's use of hand-held mobile technologies at mealtimes (see Gonçalves, Barreto, Monteiro, Zangeronimo, Castelo, van der Bilt, \& Pereira, 2019). Indeed, these technologies have been demonstrated to lead to a not insubstantial 15-30\% increase in consumption, as compared to those who eat in the absence of distracting technology. Here, one should probably also not forget the suggestion/assertion that North Americans consume as much as $20 \%$ of the food they eat while at the wheel of their car (e.g., Pollan, 2006; Steel, 2008). Over recent years, an extensive body of empirical research has shown how attention-demanding a task driving really is (see Sivak, 1996; and Spence \& Ho, 2008, for a review of attention and the senses while driving).

A number of researchers have suggested that it is the number of food-related sensations that helps determine when we stop eating, rather than necessarily the number of calories consumed (see de Graaf, 2012; Spence, 2017a). To the extent that they are right, the fact that so much of our everyday eating and drinking is undertaken while we are distracted, should give cause for concern. It would certainly seem to go against Luciano Pavarotti's (1981) suggestion from some decades ago that: "One of the very nicest things about life is the way we must regularly stop whatever it is we are doing and devote our attention to eating." (Pavarotti \& Wright, 1981). Consistent with this, there is some evidence to suggest that mindful eating (e.g., of a raisin) can enhance the tasting experience (Hong, Lishner, \& Han, 2014). Distracted dining and drinking may then be playing a more important role in the growing obesity crises than most people would seem to realize.

\section{$\underline{\text { Conclusions }}$}


To date, cognitive psychologists, and latterly cognitive neuroscientists, would not seem to have accorded the chemical senses anything like the attention that they most definitely deserve (e.g., Young, 1969). ${ }^{12}$ And, while the focus of this review has been squarely on the topic of attention, it is clear that a similar asymmetry exists in the field of multisensory research more generally. For instance, only one of the 65 chapters in Calvert, Stein, and Spence's (2004) The Handbook of Multisensory Processing addressed the chemical senses (specifically, the chapter by Stevenson \& Boakes, 2004, on learned synaesthesia between the senses of taste and smell)! What is more, somewhat depressingly the situation hasn't really changed much in any of the subsequent volumes that have reviewed progress in our understanding of multisensory information processing across the lifespan (e.g., Bremner, Lewkowicz, \& Spence, 2012; Stein, 2012). Nevertheless, given the explanatory validity and conceptual frameworks for understanding attention's role in modulating various aspects of human information processing/perception, this situation will likely start to change in the years ahead, at least as long as more cognitive psychologists/cognitive neuroscientists start to pay attention to the chemical senses in a research context.

Given that far more of the cortical real-estate is given over to the processing of visual information than it is to the processing of information in any of the other senses (see Felleman \& Van Essen, 1991; see also Gallace, Ngo, Sulaitis, \& Spence, 2012, Table 1), one might have expected that attentional resources would follow suit. Relevant here, Stevenson and Attuquayefilo (2013) have made a persuasive case for the claim that many of the distinctive features of olfactory consciousness/attention can be linked to the limited processing resources that are available to the olfactory system (see also Gagnon, Kupers, \& Ptito, 2014; Kaas, 2013). However, as has hopefully become clear in this review, the chemical senses are as susceptible to attentional manipulations as the spatial senses, despite the limited neocortical resources available for olfactory information processing (see Stevenson \& Attuquayefilo, 2013).

And beyond the way in which food-cues capture our attention, there is also recent work suggesting a link between food, hunger, and memory (Al-Shawaf, 2016). Beyond that, even

\footnotetext{
${ }^{12}$ Sometimes, in fact, it feels as though we really haven't come all that far from William James' day. In the closing years of the $19^{\text {th }}$ century, James wrote that: "Taste, smell, as well as hunger, thirst, nausea and other so-called "common" sensations need not be touched on... as almost nothing of psychological interest is known concerning them." In fact, it is not just the flavour senses that science has tended to ignore. As the eminent Oxford-based Hungarian-born physicist Nicolas Kurti once put it: "However it seemed to me that, while scientists on the whole enjoy good food \& are often expert cooks, they shy away from a serious application of their profession in the kitchen. Could it be that they do not regard cooking as sufficiently dignified to deserve research effort using scientific techniques \& methods?" (Kurti, 1988).
} 
the way in which we process information may be determined, at least in part, by food. For instance, according to Talhelm, Zhang, Oishi, Shimin, Duan, Lan, and Kitayama (2014; see also Henrich, 2014), an individual's cognitive style may be related to the kinds of food they cultivate. According to Talhelm et al.'s research, people in those parts of China where wheat is cultivated are more analytical and individualistic than those in parts of China where rice is the dominant crop. Given such intriguing findings, the hope is that more researchers will all be minded to pay attention to the chemical senses in the years ahead.

\section{REFERENCES}

Aarts, H., Dijksterhuis, A., \& De Vries, P. (2001). On the psychology of drinking: Being thirsty and perceptually ready. British Journal of Psychology, 92, 631-642.

Albrecht, J., Schreder, T., Kleemann, A. M., Schöpf, V., Kopietz, R., Anzinger, A., Demmel, M., Linn, J., Kettenmann, B., \& Wiesmann, M. (2009). Olfactory detection thresholds and pleasantness of a food-related and a non-food odour in hunger and satiety. Rhinology, 47, 160165.

Allen, F., \& Schwartz, M. (1940). The effect of stimulation of the senses of vision, hearing, taste, and smell upon the sensibility of the organs of vision. Journal of General Physiology, 24, 105-121.

Allen, J. S. (2012). The omnivorous mind: Our evolving relationship with food. London, UK: Harvard University Press.

Allman, J. M. (2000). Evolving brains. New York, NY: Scientific American Publishing.

Al-Shawaf, L. (2016). The evolutionary psychology of hunger. Appetite, 105, 591-595. doi: 10.1016/j.appet.2016.06.021

Arvisenet, G., Guichard, E., \& Ballester, J. (2016). Taste-aroma interaction in model wines: Effect of training and expertise Food Quality \& Preference, 52, 211-221.

Ashkenazi, A., \& Marks, L. E. (2004). Effect of endogenous attention on detection of weak gustatory and olfactory flavors. Perception \& Psychophysics, 66, 596-608.

Auvray, M., \& Spence, C. (2008). The multisensory perception of flavor. Consciousness and Cognition, 17, 1016-1031.

Baus, O., \& Bouchard, S. (2017). Exposure to an unpleasant odour increases the sense of presence in virtual reality. Virtual Reality, 21, 59-74.

Bellas, D. N., Novelly, R. A., Eskenazi, B., \& Wasserstein, J. (1988). The nature of unilateral neglect in the olfactory sensory system. Neuropsychologia, 26, 45-52.

Benoni, H., \& Tsal, Y. (2010). Where have we gone wrong? Perceptual load does not affect selective attention. Vision Research, 50, 1292-1298.

Benoni, H., \& Tsal, Y. (2013). Conceptual and methodological concerns in the theory of perceptual load. Frontiers in Psychology, 4:522. doi:10.3389/fpsyg.2013.00522 
Bensafi, M., Porter, J., Pouliot, S., Mainland, J., Johnson, B., Zelano, C. et al. (2003). Olfactory activity during imagery mimics that during perception. Nature Neuroscience, 6, 1142-1144.

Bielser, M.-L., Crézé, C., Murray, M. M., \& Toepel, U. (2016). Does my brain want what my eyes like? - How food liking and choice influence spatio-temporal brain dynamics of food viewing. Brain \& Cognition, 110, 64-73.

Blass, E. M., Anderson, D. R., Kirkorian, H. L., Pempek, T. A., Price, I., \& Koleini, M. F. (2006). On the road to obesity: Television viewing increases intake of high-density foods. Physiology \& Behavior, 88, 597-604.

Boakes, R. A., \& Hemberger, H. (2012). Odour-modulation of taste ratings by chefs. Food Quality and Preference, 25, 81-86.

Boesveldt, S., Frasnelli, J., Gordon, A. R., \& Lündstrom, J. N. (2010). The fish is bad: Negative food odors elicit faster and more accurate reactions than other odors. Biological Psychology, 84, 313-317.

Bojanowski, V., \& Hummel, T. (2012). Retronasal perception of odors. Physiology \& Behavior, 107, 484-487.

Boulos, R., Vikre, E. K., Oppenheimer, S., Chang, H., \& Kanarek, R. B. (2012). ObesiTV: How television is influencing the obesity epidemic. Physiology \& Behaviour, 107, 146-153.

Bragulat, V., Dzemidzic, M., Bruno, C., Cox, C. A., Talavage, T., Considine, R. V., et al. (2010). Food-related odor probes of brain reward circuits during hunger: A pilot fMRI study. Obesity, 18, 1566-1571. doi: 10.1038/oby.2010.57

Brand, G. (2006). Olfactory/trigeminal interactions in nasal chemoreception. Neuroscience \& Biobehavioral Reviews, 30, 908-917.

Braude, L., \& Stevenson, R. J. (2014). Watching television while eating increases energy intake. Examining the mechanisms in female participants. Appetite, 76, 9-16.

Bremner, A., Lewkowicz, D., \& Spence, C. (Eds.). (2012). Multisensory development. Oxford, UK: Oxford University Press.

Brignell, C., Griffiths, T., Bradley, B. P., \& Mogg, K. (2009). Attentional and approach biases for pictorial food cues. Influence of external eating. Appetite, 52, 299-306.

Bruner, J. S., \& Goodman, C. C. (1947). Value and need as organizing factors in perception. The Journal of Abnormal and Social Psychology, 42, 33-44.

Bult, J. H. F., de Wijk, R. A., \& Hummel, T. (2007). Investigations on multimodal sensory integration: Texture, taste, and ortho- and retronasal olfactory stimuli in concert. Neuroscience Letters, 411, 6-10.

Burzynska, J., Wang, Q. J., Spence, C., \& Bastian, S. E. P. (2019). Taste the bass: Low frequencies increase the perception of body and aromatic intensity in red wine. Multisensory Research. DOI:10.1163/22134808-20191406.

Callan, A., Callan, D., \& Ando, H. (2018). Differential effects of music and pictures on taste perception - an fMRI study. Poster presented at the Annual Meeting of the International Multisensory Research Forum. June, 14-17 $7^{\text {th }}$ June, Toronto, CA.

Calvert, G. A., Spence, C., \& Stein, B. E. (Eds.). (2004). The handbook of multisensory processing. Cambridge, MA: MIT Press.

Carrasco, M., Ling, S., \& Read, S. (2004). Attention alters appearance. Nature Neuroscience, 7, 308-313. 
Castellanos, E. H., Charboneau, E., Dietrich, M. S., Park, S., Bradley, B. P., Mogg, K., et al. (2009). Obese adults have visual attention bias for food cue images: Evidence for altered reward system function. International Journal of Obesity, 33, 1963-1973.

Changizi, M. A., \& Hall, W. G. (2001). Thirst modulates a perception. Perception, 30, 14891497.

Channon, S., \& Hayward, A. (1990). The effect of short-term fasting on processing of food cues in normal subjects. International Journal of Eating Disorders, 9, 447-452.

Chen, J., Papies, E. K., \& Barsalou, L. W. (2016). A core eating network and its modulations underlie diverse eating phenomena. Brain and Cognition, 110, 20-42.

Chen, K., Zhou, B., Chen, S., He, S., \& Zhou, W. (2013). Olfaction spontaneously highlights visual saliency map. Proceedings of the Royal Society B. Biological Sciences, 280(1768):20131729.

Cinel, C., Humphreys, G. W., \& Poli, R. (2002). Cross-modal illusory conjunctions between vision and touch. Journal of Experimental Psychology: Human Perception \& Performance, 28, 1243-1266.

Cohen, A., \& Ivry, R. (1989). Illusory conjunctions inside and outside the focus of attention. Journal of Experimental Psychology: Human Perception and Performance, 15, 650-663.

de Graaf, C. (2012). Texture and satiation: The role of oro-sensory exposure time. Physiology \& Behavior, 107, 496-501.

Delwiche, J. F., Lera, M. F., \& Breslin, P. A. S. (2000). Selective removal of a target stimulus localized by taste in humans. Chemical Senses, 25, 181-187.

Demattè, M. L., Österbauer, R., \& Spence, C. (2007). Olfactory cues modulate judgments of facial attractiveness. Chemical Senses, 32, 603-610.

Deroy, O., Crisinel, A.-S., \& Spence, C. (2013). Crossmodal correspondences between odors and contingent features: Odors, musical notes, and geometrical shapes. Psychonomic Bulletin \& Review, 20, 878-896. doi 10.3758/s13423-013-0397-0.

Dinh, H. Q., Walker, N., Hodges, L. F., Song, C., \& Kobayashi, A. (1999). Evaluating the importance of multi-sensory input on memory and the sense of presence in virtual environments. Proceedings of IEEE Virtual Reality Conference 1999, Houston, TX, 13-17 March (pp. 222-228).

Driver, J. (2001). A selective review of selective attention research from the past century. British Journal of Psychology, 92, 53-78.

Duclaux, R., Feisthauer, J., \& Cabanac, M. (1973). Effect of eating a meal on the pleasantness of food and non-food odors in man. Physiology \& Behavior, 10, 1029-1033.

Ernst, M. O. (2012). Optimal multisensory integration: Assumptions and limits. In B. E. Stein (Ed.), The new handbook of multisensory perception (pp. 527-543). Cambridge, MA: MIT Press.

Ernst, M. O., \& Bülthoff, H. H. (2004). Merging the senses into a robust percept. Trends in Cognitive Sciences, 8, 162-169.

Fadardi, J. S., \& Bazzaz, M. M. (2011). A Combi-Stroop test for measuring food-related attentional bias. Experimental \& Clinical Psychopharmacology, 19, 371-377. 
Felleman, D. J., \& Van Essen, D. C. (1991). Distributed hierarchical processing in primate cerebral cortex. Cerebral Cortex, 1, 1-47.

Forster, S., \& Spence, C. (2018). "What smell?" Temporarily loading visual attention induces a prolonged loss of olfactory awareness. Psychological Science, 29, 1642-1652.

Franceroni, S. L. (2013). The nature and status of visual resources. In D. Reisberg (Ed.), The Oxford handbook of cognitive psychology (pp. 1-28). Oxford, UK: Oxford University Press.

Frost, R., Quinones, I., Veldhuizen, M., Alava, J.-I., Small, D., \& Carreiras, M. (2015). What can the brain teach us about winemaking? An fMRI study of alcohol level preferences. PLoS ONE, 10(3):e0119220.

Gagnon, L., Kupers, R., \& Ptito, M. (2014). Making sense of the chemical senses. Multisensory Research, 27, 399-419.

Gallace, A., Ngo, M. K., Sulaitis, J., \& Spence, C. (2012). Multisensory presence in virtual reality: Possibilities \& limitations. In G. Ghinea, F. Andres, \& S. Gulliver (Eds.), Multiple sensorial media advances and applications: New developments in MulSeMedia (pp. 1-40). Hershey, PA: IGI Global.

Geisler, M. W., \& Murphy, C. (2000). Event-related brain potentials to attended and ignored olfactory and trigeminal stimuli. International Journal of Psychophysiology, 37, 309-315.

Gibson, J. J. (1966). The senses considered as perceptual systems. Boston, MA: Houghton Mifflin.

Gilchrist, J. C., \& Nesberg, L. S. (1952). Need and perceptual change in need-related objects. Journal of Experimental Psychology, 44, 369-376.

Giles, G. E., Avanzato, B. F., Mora, B., Jurdak, N. A., \& Kanarek, R. B. (2018). Sugar intake and expectation effects on cognition and mood. Experimental Clinical Psychopharmacology, 26, 302-309. doi: 10.1037/pha0000182

Ginieis, R., Franz, E. A., Oey, I., \& Peng, M. (2018). The "sweet" effect: Comparative assessments of dietary sugars on cognitive performance. Physiology \& Behavior, 184, 242247. doi: 10.1016/j.physbeh.2017.12.010

Gonçalves, R. F. da M., Barreto, D. de A., Monteiro, P. I., Zangeronimo, M. G., Castelo, P. M., van der Bilt, A., \& Pereira, L. J. (2019). Smartphone use while eating increases caloric ingestion. Physiology \& Behavior, 204, 93-99.

González, J., Barros-Loscertales, A., Pulvermüller, F., Meseguer, V., Sanjuán, A., Belloch, V., et al. (2006). Reading cinnamon activates olfactory brain regions. NeuroImage, 32, 906-912.

Gore, S. A., Foster, J. A., DiLillo, V. G., Kirk, K., \& Smith West, D. (2003). Television viewing and snacking. Eating Behaviors, 4, 399-405.

Gottfried, J. A., \& Dolan, R. J. (2003). The nose smells what the eye sees: Crossmodal visual facilitation of human olfactory perception. Neuron, 39, 375-386.

Grabenhorst, F., Rolls, E. T., \& Bilderbeck, A. (2008). How cognition modulates affective responses to taste and flavor: Top-down influences on the orbitofrontal and pregenul cortices. Cerebral Cortex, 18, 1549-1559.

Grabenhorst, F., Rolls, E. T., \& Margot, C. (2011). A hedonically complex odor mixture produces an attentional capture effect in the brain. NeuroImage, 55, 832-843. 
Harrar, V., Toepel, U., Murray, M., \& Spence, C. (2011). Food's visually-perceived fat content affects discrimination speed in an orthogonal spatial task. Experimental Brain Research, 214, 351-356.

Henrich, J. (2014). Rice, psychology, and innovation. Science, 344, 593-594.

Ho, C., \& Spence, C. (2005). Olfactory facilitation of dual-task performance. Neuroscience Letters, 389, 35-40.

Hoffman, H. G., Hollander, A., Schroder, K., Rousseau, S., \& Furness, T. I. (1998). Physically touching and tasting virtual objects enhances the realism of virtual experiences. Journal of Virtual Reality, 3, 226-234.

Hong, P. Y., Lishner, D. A., \& Han, K. H. (2014). Mindfulness and eating: An experiment examining the effect of mindful raisin eating on the enjoyment of sampled food. Mindfulness, 5, 80-87.

Iannilli, E., DelGratta, C., Gerber, J. C., Romani, G. L., \& Hummel, T. (2008). Trigeminal activation using chemical, electrical, and mechanical stimuli. Pain, 139, 376-388.

Ilmberger, J., Heuberger, E., Mahrhofer, C., Dessovic, H., Kowarik, D., \& Buchbauer, G. (2001). The influence of essential oils on human attention. 1: Alertness. Chemical Senses, 26, 239-245.

Ischer, M., Baron, N., Mermoud, C., Cayeux, I., Porcherot, C., Sander, D., \& Delplanque, S. (2014). How incorporation of scents could enhance immersive virtual experiences. Frontiers in Psychology, 5:736.

James, W. (1890). Principles of psychology. New York, NY: Henry Holt.

Jensen, A., Merz, S., Spence, C., \& Frings, C. (2019). Overt spatial attention modulates multisensory selection. Journal of Experimental Psychology: Human Perception \& Performance, 45, 174-188.

Jinks, A., \& Laing, D. G. (1999). Temporal processing reveals a mechanism for limiting the capacity of humans to analyze mixtures. Cognitive Brain Research, 8, 311-325.

Jones, L., Bowers, C. A., Washburn, D., Cortes, A., \& Satya, R. V. (2004). The effect of olfaction on immersion into virtual environments. In Human performance, situation awareness and automation: Issues and considerations for the $21^{\text {st }}$ Century (pp. 282-285). Hillsdale, NJ: Lawrence Erlbaum Associates.

Kaas, J. H. (2013). The evolution of brains from early mammals to humans. WIREs Cognitive Science, 4, 33-45. doi:10.1002/wcs.1206

Keller, A. (2011). Attention and olfactory consciousness. Frontiers in Psychology. 2:380. doi: 10.3389/fpsyg.2011.00380

Knoeferle, K., Knoeferle, P., Velasco, C., \& Spence, C. (2016). Multisensory brand search: How the meaning of sounds guides consumers' visual attention. Journal of Experimental Psychology: Applied, 22, 196-210.

Knöferle, K. M., \& Spence, C. (2012). Crossmodal correspondences between sounds and tastes. Psychonomic Bulletin \& Review, 19, 992-1006.

Krishna, A., Morrin, M., \& Sayin, E. (2014). Smellizing cookies and salivating: A focus on olfactory imagery. Journal of Consumer Research, 41, 19-36. 
Kurti, N. (1988). Introduction. In N. Kurti \& G. Kurti (Eds.), But the crackling is superb: An anthology on food and drink by fellows and foreign members of the Royal Society (pp. 1-4). Bristol, UK: Institute of Physics Publications.

Kuznicki, J. T., Hayward, M., \& Schultz, J. (1983). Perceptual processing of taste quality. Chemical Senses, 7, 273-292.

Kuznicki, J. T., \& Turner, L. S. (1986). Reaction time in the perceptual processing of taste quality. Chemical Senses, 11, 183-201.

LaBar, K. S., Gitelman, D. R., Parrish, T. B., Kim, Y. H., Nobre, A. C., \& Mesulam, M. M. (2001). Hunger selectively modulates corticolimbic activation to food stimuli in humans. Behavioral Neuroscience, 115, 493-500.

Labbe, D., Gilbert, F., \& Martin, N. (2008). Impact of olfaction on taste, trigeminal, and texture perceptions. Chemosensory Perception, 1, 217-226. doi:10.1007/s12078-008-9029-x

LaBerge, D. (1995). Attentional processing. Cambridge, MA: Harvard University Press.

Lacey, S., \& Lawson, R. (Eds.). (2013). Multisensory imagery. New York, NY: Springer.

Laing, D. G., \& Glemarec, A. (1987). Selective attention and the perceptual analysis of odor mixtures. Physiology \& Behavior, 52, 1047-1053.doi:10.1016/0031- 9384(92)90458-E

Lavie, N. (1995). Perceptual load as a necessary condition for selective attention. Journal of Experimental Psychology: Human Perception \& Performance, 21, 451-468.

Lavie, N. (2005). Distracted and confused?: Selective attention under load. Trends in Cognitive Sciences, 9, 75-82.

Lavy, E. H., \& van den Hout, M. A. (1993). Attentional bias for appetitive cues: Effects of fasting in normal subjects. Behavioral Cognitive Psychotherapy, 21, 297-310. doi: $10.1017 / \mathrm{S} 1352465800011632$

Lazarus, R. S., Yousem, H., \& Arenberg, D. (1953). Hunger and perception. Journal of Personality, 21, 312-328. doi: 10.1111/j.1467-6494.1953.tb01774.x

Lennie, P. (2003). The cost of cortical computation. Current Biology, 13, 493-497.

Li, W., Moallem, I., Paller, K. A., \& Gottfried, J. A. (2007). Subliminal smells can guide social preferences. Psychological Science, 18, 1044-1049.

Lim, J., \& Green, B. G. (2008). Tactile interaction with taste localization: Influence of gustatory quality and intensity. Chemical Senses, 33, 137-143.

Lin, Y. H. T., Hamid, N., Shepherd, D., Kantono, K., \& Spence, C. (2019). Background sounds influence the multisensory perception of chocolate gelati. Foods, 8:124; doi:10.3390/foods8040124.

Loeber, S., Grosshans, M., Herpertz, S., Kiefer, F., \& Herpertz, S. C. (2013). Hunger modulates behavioral disinhibition and attention allocation to food-associated cues in normal-weight controls. Appetite, 71, 32-39. doi: 10.1016/j. appet.2013.07.008

Lundström, J. N., Boesveldt, S., \& Albrecht, J. (2011). Central processing of the chemical senses: An overview. ACS Chemical Neuroscience, 2, 5-16.

Macdonald, J. S., \& Lavie, N. (2011). Visual perceptual load induces inattentional deafness. Attention, Perception, \& Psychophysics, 73, 1780-1789.

Marks, L. E. (2002). The role of attention in chemosensation. Food Quality and Preference, 14, 147-155. 
Marks, L. E., Elgart, B. Z., Burger, K., \& Chakwin, E. M. (2007). Human flavour perception: Application of information integration theory. Teor Model, 1, 121-132.

Marks, L. E., \& Wheeler, M. E. (1998). Attention and the detectability of weak taste stimuli. Chemical Senses, 23, 19-29.

Martin, D. (2007). Évolution. Lausanne, France: Editions Favre.

Masumoto, D. M. (2003). Four seasons in five senses: Things worth savouring. New York, NY: W. W. Norton \& Co.

McCormick, D. A., \& Bal, T. (1994). Sensory gating mechanisms of the thalamus. Current Opinion in Neurobiology, 4, 550-556.

McGann, J. P. (2017). Poor human olfaction is a 19th-century myth. Science, 356, eaam7263.

Meyners, M., Castura, J. C., \& Carr, B. T. (2013). Existing and new approaches for the analysis of CATA data. Food Quality and Preference, 30, 309-319.

Michael, G. A., Jacquot, L., Millot, J.-L., \& Brand, G. (2003). Ambient odors modulate visual attentional capture. Neuroscience Letters, 352, 221-225.

Michael, G. A., Jacquot, L., Millot, J.-L., \& Brand, G. (2005). Ambient odors influence the amplitude and time course of visual distraction. Behavioral Neuroscience, 119, 708-715.

Mogg, K., Bradley, B. P., Hyare, H., \& Lee, S. (1998) Selective attention to food-related stimuli in hunger: Are attentional biases specific to emotional and psychopathological states, or are they also found in normal drive states? Behavior Research Therapy, 36, 227-237.

Murphy, S., Dalton, P., \& Spence, C. (2017a). Selective attention in vision, audition, and touch. In R. Menzel (Ed.), Learning theory and behavior, Vol. 1 of Learning and memory: A comprehensive reference, $2^{\text {nd }}$ Ed., J. Byrne (Series Ed.) (pp. 155-170). Oxford, UK: Academic Press. http://dx.doi.org/10.1016/B978-0-12-809324-5.21010-9.

Murphy, S., Spence, C., \& Dalton, P. (2017b). Auditory perceptual load: A critical review. Hearing Research, 352, 40-48.

Navon, D. (1984). Resources: A theoretical soup stone? Psychological Review, 91, 216-234.

Newman, J. (1995). Thalamic contributions to attention and consciousness. Consciousness and Cognition, 4, 172-193.

Nijs, I. M., Muris, P., Euser, A. S., \& Franken, I. H. (2010). Differences in attention to food and food intake between overweight/obese and normal-weight females under conditions of hunger and satiety. Appetite, 54, 243-254.

Nitschke, J. B., Dixon, G. E., Sarinopoulos, I., Short, S. J., Cohen, J. D., Smith, E. E., Kosslyn, S. M., Rose, R. M., \& Davidson, R. J. (2006). Altering expectancy dampens neural response to aversive taste in primary taste cortex. Nature Neuroscience, 9, 435-442.

Ohla, K., Toepel, U., le Coutre, J., \& Hudry, J. (2012). Visual-gustatory interaction: Orbitofrontal and insular cortices mediate the effect of high-calorie visual food cues on taste pleasantness. PLoS ONE, 7(3): e32434.

Oliver, P. Cicerale, S., Pang, E., \& Keast, R. (2018). Check-all-that-applies as an alternative for descriptive analysis to establish flavors driving liking in strawberries. Journal of Sensory Studies, 2018;33:e12316. https://doi.org/10.1111/joss.12316.

Pavarotti, L., \& Wright, W. (1981). Pavarotti: My own story. Garden City, NY: Doubleday. 
Pazart, L., Comte, A., Magnin, E., Millot, J.-L., \& Moulin, T. (2014). An fMRI study on the influence of sommeliers' expertise on the integration of flavor. Frontiers in Behavioral Neuroscience, 8:358.

Piech, R. M., Pastorino, M. T., \& Zald, D. H. (2010). All I saw was the cake. Hunger effects on attentional capture by visual food cues. Appetite, 54, 579-582.

Plailly, J., Howard, J. D., Gitelman, D. R., \& Gottfried, J. A. (2008). Attention to odor modulates thalamocortical connectivity in the human brain. Journal of Neuroscience, 28, 52575267.

Pollan, M. (2006). The omnivore's dilemma: A natural history of four meals. New York, NY: Penguin Press.

Portas, C. M., Rees, G., Howseman, A., Josephs, O., Turner, R., \& Frith, C. (1998). A specific role for the thalamus in mediating the interaction of attention and arousal in humans. Journal of Neuroscience, 18, 8979-8989.

Porter, J., Craven, B., Khan, R. M., Chang, S. J., Kang, I., Judkewitz, B., Volpe, J., Settles, G., $\&$ Sobel, N. (2007). Mechanisms of scent-tracking in humans. Nature Neuroscience, 10, 2729.

Posner, M. I. (1978). Chronometric explorations of mind. Hillsdale, NJ: Erlbaum.

Posner, M. I., Nissen, M. J., \& Klein, R. M. (1976). Visual dominance: An informationprocessing account of its origins and significance. Psychological Review, 83, 157-171.

Prescott, J. (2004). Psychological processes in flavour perception. In A. Taylor \& D. Roberts (Eds.), Flavour perception (pp. 256-277). Oxford, UK: Blackwell.

Price, J. L. (1985). Beyond the primary olfactory cortex: Olfactory-related areas in the neocortex, thalamus and hypothalamus. Chemical Senses, 10, 239-258.

Qureshy, A., Kawashima, R., Imran, M. B., Sugiura, M., Goto, R., Okada, K. et al. (2000). Functional mapping of human brain in olfactory processing: A PET study. Journal of Neurophysiology, 84, 1656-1666.

Rabin, M. D., \& Cain, W. S. (1989). Attention and learning in the perception of odor mixtures. In D. G. Laing, W. S., Cain, R. L. McBride, \& B. W. Ache (Eds.), Perception of complex smells and tastes (pp. 173-188). Sydney, Australia: Academic Press.

Radel, R., \& Clément-Guillotin, C. (2012). Evidence of motivational influences in early visual perception hunger modulates conscious access. Psychological Science, 23, 232-234.

Ranasinghe, N., Cheok, A., Nakatsu, R., \& Do, E. Y.-L. (2013). Simulating the sensation of taste for immersive experiences. In Proceedings of the 2013 ACM Multimedia, International workshop on Immersive media experiences (ImmersiveMe '13) (pp. 29-34). ACM Multimedia, 2013, New York, NY, USA. DOI=10.1145/2512142.2512148 http://doi.acm.org/10.1145/2512142.2512148

Rozin, P. (1982). "Taste-smell confusions" and the duality of the olfactory sense. Perception \& Psychophysics, 31, 397-401.

Sawada, R., Sato, W., Toichi, M., \& Fushiki, T. (2017). Fat content modulates rapid detection of food: A visual search study using fast food and Japanese diet. Frontiers in Psychology, 8:1033. doi: 10.3389/fpsyg.2017.01033

Schreiber, T., \& White, T. L. (2013). Detect, reject, focus: The role of satiation and odor relevance in cross-modal attention. Chemosensory Perception, 6, 170-178. 
Segal, S. J., \& Fusella, V. (1970). Influence of imagined pictures and sounds on detection of visual and auditory signals. Journal of Experimental Psychology, 83, 458-464.

Segal, S. J., \& Fusella, V. (1971). Effect of images in six sense modalities on detection of visual signal from noise. Psychonomic Science, 24, 55-56.

Seigneuric, A., Durand, K., Jiang, T., Baudouin, J.-Y., \& Schaal, B. (2010). The nose tells it to the eyes: Crossmodal associations between olfaction and vision. Perception, 39, 1541-1554.

Sela, L., \& Sobel, N. (2010). Human olfaction: A constant state of change-blindness. Experimental Brain Research, 205, 13-29.

Seo, H.-S., Roidl, E., Müller, F., \& Negoias, S. (2010). Odors enhance visual attention to congruent objects. Appetite, 54, 544-549.

Shepard, G. M. (2005). Perception without a thalamus: How does olfaction do it? Neuron, 46, 166-168.

Siep, N., Roefs, A., Roebroeck, A., Havermans, R., Bonte, M. L., \& Jansen, A. (2009). Hunger is the best spice: An fMRI study of the effects of attention, hunger and calorie content on food reward processing in the amygdala and orbitofrontal cortex. Behavioural Brain Research, 198, 149-158.

Silver, W. L., \& Maruniak, J. A. (1981). Trigeminal chemoreception in the nasal and oral cavities. Chemical Senses, 6, 295-305.

Sivak, M. (1996). The information that drivers use: Is it indeed 90\% visual? Perception, 25, 1081-1089.

Small, D. M. (2012). Flavor is in the brain. Physiology and Behavior, 107, 540-552.

Small, D. M., Veldhuizen, M. G., Felsted, J., Mak, Y. E., \& McGlone, F. (2008). Separable substrates for anticipatory and consummatory food chemosensation. Neuron, 57, 786-797.

Smythies, J. (1997). The functional neuroanatomy of awareness: With a focus on the role of various anatomical systems in the control of intermodal attention. Consciousness and Cognition, 6, 455-481.

Spence, C. (2011). Mouth-watering: The influence of environmental and cognitive factors on salivation and gustatory/flavour perception. Journal of Texture Studies, 42, 157-171.

Spence, C. (2014). Orienting attention: A crossmodal perspective. In A. C. Nobre \& S. Kastner (Eds.), The Oxford handbook of attention (pp. 446-471). Oxford, UK: Oxford University Press.

Spence, C. (2015a). Eating with our ears: Assessing the importance of the sounds of consumption to our perception and enjoyment of multisensory flavour experiences. Flavour, 4:3.

Spence, C. (2015b). Multisensory flavour perception. Cell, 161, 24-35.

Spence, C. (2015c). On the psychological impact of food colour. Flavour, 4:21.

Spence, C. (2016a). Oral referral: On the mislocalization of odours to the mouth. Food Quality \& Preference, 50, 117-128.

Spence, C. (2016b). The neuroscience of flavor. In B. Piqueras-Fiszman \& C. Spence (Eds.), Multisensory flavor perception: From fundamental neuroscience through to the marketplace (pp. 235-248). Oxford, UK: Elsevier.

Spence, C. (2017a). Gastrophysics: The new science of eating. London, UK: Viking Penguin. 
Spence, C. (2017b). Sonic seasoning. In L. Minsky \& C. Fahey (Eds.), Audio branding: Using sound to build your brand (pp. 52-58). London, UK: Kogan Page.

Spence, C. (2018). Why is piquant/spicy food so popular? International Journal of Gastronomy \& Food Science, 12, 16-21.

Spence, C. (2018). Crossmodal contributions to the perception of piquancy/spiciness. Journal of Sensory Studies, 2018:e12476.

Spence, C. [J.], \& Driver, J. (1994). Covert spatial orienting in audition: Exogenous and endogenous mechanisms. Journal of Experimental Psychology: Human Perception and Performance, 20, 555-574.

Spence, C., \& Driver, J. (Eds.). (2004). Crossmodal space and crossmodal attention. Oxford, UK: Oxford University Press.

Spence, C., \& Frings, C. (in press). Multisensory feature integration in (and out) of the focus of spatial attention. Attention, Perception, \& Psychophysics.

Spence, C., \& Ho, C. (2008). Crossmodal information processing in driving. In C. Castro (Ed.), Human factors of visual performance in driving (pp. 187-200). Boca Raton, FL: CRC Press.

Spence, C., Kettenmann, B., Kobal, G., \& McGlone, F. P. (2000). Selective attention to the chemosensory modality. Perception \& Psychophysics, 62, 1265-1271.

Spence, C., Kettenmann, B., Kobal, G., \& McGlone, F. P. (2001a). Attention to olfaction: A psychophysical investigation. Experimental Brain Research, 138, 432-437.

Spence, C., Kettenmann, B., Kobal, G., \& McGlone, F. P. (2001b). Shared attentional resources for processing vision and chemosensation. Quarterly Journal of Experimental Psychology, 54A, 775-783.

Spence, C., Mancini, M., \& Huisman, G. (submitted). Digital commensality: On the pros and cons of eating and drinking with technology. Frontiers in Psychology.

Spence, C., Nicholls, M. E. R., \& Driver, J. (2001). The cost of expecting events in the wrong sensory modality. Perception \& Psychophysics, 63, 330-336.

Spence, C., \& Piqueras-Fiszman, B. (2016). Oral-somatosensory contributions to flavor perception and the appreciation of food and drink. In B. Piqueras-Fiszman \& C. Spence (Eds.), Multisensory flavor perception: From fundamental neuroscience through to the marketplace (pp. 59-79). Duxford, CB: Elsevier.

Spence, C., Reinoso-Carvalho, F., Velasco, C., \& Wang, Q. J. (2019). Extrinsic auditory contributions to food perception \& consumer behaviour: An interdisciplinary review. Multisensory Research. DOI:10.1163/22134808-20191403.

Spence, C., Reinoso-Carvalho, F., Velasco, C., \& Wang, Q. J. (in press). Introduction to the Special Issue: Auditory contributions to food perception and consumer behaviour. Multisensory Research.

Spence, C., Smith, B., \& Auvray, M. (2015). Confusing tastes and flavours. In D. Stokes, M. Matthen, \& S. Biggs (Eds.), Perception and its modalities (pp. 247-274). Oxford, UK: Oxford University Press.

Spence, C., \& Wang, Q. J. (2018). On the meaning(s) of complexity in the chemical senses. Chemical Senses, 43, 451-461.

Spence, C., Wang, (Q.) J., \& Youssef, J. (2017). Pairing flavours and the temporal order of tasting. Flavour, 6:4. DOI 10.1186/s13411-017-0053-0 http://rdcu.be/pStQ 
Steel, C. (2008). Hungry city: How food shapes our lives. London, UK: Chatto \& Windus.

Stein, B. E. (Ed.-in-chief). (2012). The new handbook of multisensory processing. Cambridge, MA: MIT Press.

Stevenson, R. J. (2009). The psychology of flavour. Oxford, UK: Oxford University Press.

Stevenson, R. J. (2012). The role of attention in flavour perception. Flavour, 1:2.

Stevenson, R. J. (2014a). Flavor binding: Its nature and cause. Psychological Bulletin, 140, 487-510.

Stevenson, R. J. (2014b). Object concepts in the chemical senses. Cognitive Science, 38(7), 1360-1383. doi: 10.1111/cogs.12111.

Stevenson, R. J. (2016). Attention and flavour binding. In B. Piqueras-Fiszman \& C. Spence (Eds.), Multisensory flavor perception: From fundamental neuroscience through to the marketplace (pp. 15-36). Duxford: Elsevier.

Stevenson, R. J., \& Attuquayefilo, T. (2013). Human olfactory consciousness and cognition: Its unusual features may not result from unusual functions but from limited neocortical processing resources. Frontiers in Psychology, 4:819.

Stevenson, R. J., \& Boakes, R. A. (2004). Sweet and sour smells: Learned synaesthesia between the senses of taste and smell. In G. A. Calvert, C. Spence, \& B. E. Stein (Eds.), The handbook of multisensory processing (pp. 69-83). Cambridge, MA: MIT Press.

Stevenson, R. J., \& Case, T. I. (2005). Olfactory imagery: A review. Psychonomic Bulletin \& Review, 12, 244-264.

Stevenson, R. J., Mahmut, M. K., \& Oaten, M. J. (2011). The role of attention in the localization of odors to the mouth. Attention, Perception \& Psychophysics, 73, 247-258.

Stockburger, J., Schmälzle, R., Flaisch, T., Bublatzky, F., \& Schupp, H. (2009). The impact of hunger on food cue processing: An event-related brain potential study. Neuroimage, 47, 18191829.

Stone, H., Williams, B., \& Carregal, J. A. (1968). The role of the trigeminal nerve in olfaction. Experimental Neurology, 21, 11-19.

Styles, E. A. (2006). The psychology of attention ( $2^{\text {nd }}$ Ed.). Hove, UK: Psychology Press.

Talhelm, T., Zhang, X., Oishi, S., Shimin, C., Duan, D., Lan, X., \& Kitayama, S. (2014). Large-scale psychological differences within China explained by rice versus wheat agriculture. Science, 344, 603-608.

Tham, W., Stevenson, R. J., \& Miller, L. (2009). The functional role of the mediodorsal thalamic nucleus in olfaction. Brain Research Review, 62, 109-126. doi: 10.1016/j.brainresrev.2009.09.007

Tham, W. W. P., Stevenson, R. J., \& Miller, L. A. (2011). The role of the mediodorsal thalamic nucleus in human olfaction. Neurocase, 17, 148-159.

Thesen, T., Vibell, J. F., Calvert, G. A., \& Österbauer, R. A. (2004). Neuroimaging of multisensory processing in vision, audition, touch, and olfaction. Cognitive Processing, 5, 8493.

Titchener, E. B. (1908). Lectures on the elementary psychology of feeling and attention. New York, NY: Macmillan.

Titchener, E. B. (1909). A textbook of psychology. New York, NY: Macmillan. 
Toepel, U., Knebel, J., Hudry, J., Lecoutre, J., \& Murray, M. (2009). The brain tracks the energetic value in food images. NeuroImage, 44, 967-974.

Treisman, A. M., \& Gelade, G. (1980). A feature-integration theory of attention. Cognitive Psychology, 12, 97-136.

Treisman, A., \& Schmidt, H. (1982). Illusory conjunctions in the perception of objects. Cognitive Psychology, 14, 107-141.

Tsal, Y., \& Benoni, H. (2010). Diluting the burden of load: Perceptual load effects are simply dilution effects. Journal of Experimental Psychology: Human Perception and Performance, 36, 1645-1657.

Van der Wal, R. C., \& van Dillen, L. F. (2013). Leaving a flat taste in your mouth: Task load reduces taste perception. Psychological Science, 24, 1277-1284.

van Ee, R., van Boxtel, J. J. A., Parker, A. L., \& Alais, D. (2009). Multimodal congruency as a mechanism for willful control over perceptual awareness. Journal of Neuroscience, 29, 11641-11649.

Veldhuizen, M., Shephard, T. G., Wang, M.-F., \& Marks, L. E. (2010). Coactivation of gustatory and olfactory signals in flavor perception. Chemical Senses, 35, 121-133.

Veldhuizen, M., \& Small, D. M. (2011). Modality specific neural effects of selective attention to taste and odor. Chemical Senses, 36, 747-760.

von Békésy, G. (1963). Interaction of paired sensory stimuli and conduction in peripheral nerves. Journal of Applied Physiology, 18, 1276-1284.

Wachowiak, M. (2011). All in a sniff: Olfaction as a model for active sensing. Neuron, 71, 962-973.

Wahn, B., Murali, S., Sinnett, S., \& König, P. (2017). Auditory stimulus detection partially depends on visuospatial attentional resources. i-Perception, 8:1.

Wang, G.-J., Volkow, N. D., Telang, F., Jayne, M., Ma, J., Rao, M., Zhu, W., Wong, C. T., Pappas, N. R., Geliebter, A., et al. (2004). Exposure to appetitive food stimuli markedly activates the human brain. NeuroImage, 212, 1790-1797.

Wang, Q. J., Mesz, B., Riera, P., Trevisan, M., Sigman, M., Guha, A., \& Spence, C. (2019). Analysing the impact of music on the perception of red wine via Temporal Dominance of Sensations. Multisensory Research. DOI:10.1163/22134808-20191401.

Wang, Q. J., Mesz, B., \& Spence C. (2017). Analysing the impact of music on basic taste perception using Time Intensity Analysis. MHFI'17- Proceedings of the 2nd ACM SIGCHI International Workshop on Multisensory Approaches to Human-Food Interaction, Co-located with ICMI 2017. 18-22. 13 Nov 2017.

Warm, J. S., Dember, W. N., \& Parasuraman, R. (1991). Effects of olfactory stimulation on performance and stress in a visual sustained attention task. Journal of the Society for Cosmetic Chemists, 42, 199-210.

Weil, R. L. (2007). Debunking critics' wine words: Can amateurs distinguish the smell of asphalt from the taste of cherries? Journal of Wine Economics, 2(2), 136-144.

Weng, X., Lin, Q., Ma, Y., Peng, Y., Hu, Y., Zhou, K., Shen, F., Wang, H., \& Wang, Z. (2019). Effects of hunger on visual perception in binocular rivalry. Frontiers in Psychology, 10:418. doi: 10.3389/fpsyg.2019.00418 
Wilton, M., Stancak, A., Giesbrecht, T., Thomas, A., \& Kirkham, T. (2018). Intensity expectation modifies gustatory evoked potentials to sweet taste: Evidence of bidirectional assimilation in early perceptual processing. Psychophysiology, 2018;e13299.

Wolraich, M. L., Wilson, D. B., \& White, J. W. (1995). The effect of sugar on behavior or cognition in children. A meta-analysis. JAMA, 274, 1617-1621. doi: 10.1001/jama.1995.03530200053037

Woods, A. T., Lloyd, D. M., Kuenzel, J., Poliakoff, E., Dijksterhuis, G. B., \& Thomas, A. (2011). Expected taste intensity affects response to sweet drinks in primary taste cortex. Neuroreport, 22, 365-369.

Wrangham, R. (2010). Catching fire: How cooking made us human. London, UK: Profile Books.

Xu, Y., Hamid, N., Shepherd, D., Kantono, K., \& Spence, C. (in press). Changes in flavour, emotion and electrophysiological measurements when chocolate ice cream is consumed in different eating environments. Food Research International.

Young, J. Z. (1968). Influence of the mouth on the evolution of the brain. In P. Person (Ed.), Biology of the mouth: A symposium presented at the Washington meeting of the American Association for the Advancement of Science, 29-30 December 1966 (pp. 21-35). Washington, DC: American Association for the Advancement of Science.

Zelano, C., Bensafi, M., Porter, J., Mainland, J., Johnson, B., Bremner, E., Telles, C., Khan, R., \& Sobel, N. (2005). Attentional modulation in human primary olfactory cortex. Nature Neuroscience, $8,114-120$.

Zhou, W., Jiang, Y., He, S., \& Chen, D. (2010). Olfaction modulates visual perception in binocular rivalry. Current Biology, 20, 1356-1358.

Zhou, W., Zhang, X., Chen, J., Wang, L., \& Chen, D. (2012). Nostril-specific olfactory modulation of visual perception in binocular rivalry. Journal of Neuroscience, 32, 1722517229.

Zverev, Y. P. (2004). Effects of caloric deprivation and satiety on sensitivity of the gustatory system. BMC Neuroscience, 5:5. https://doi.org/10.1186/1471-2202-5-5. 


\section{FIGURE LEGENDS}

Figure 1. Results of Wang et al.s (2004) study highlighting the widespread increase in cerebral blood flow documented in hungry participants shown images of their favourite foods. (Note that Q-tips carrying the flavour of the food were also rubbed against the participant's lips.) Interestingly, the greatest neural activation appears to be associated with the anticipation of food. As soon as the food is being consumed, any food-related neural activation tends to decline significantly (Small, Veldhuizen, Felsted, Mak, \& McGlone, 2008). In fact, separately, it has been suggested that nothing else gets the brain quite so excited (we might say, uses so many resources). That said, there continues to be fundamental uncertainty about what exactly neural processing recourses actually are [Figure reporinted from Wang et al. (2004).]

Figure 2. A pair of the images (one food-related, the other not) shown to Chinese participants in Weng et al.'s (2019) study of the effects of hunger on binocular rivalry. [Figure reprinted from Weng et al. (2019).]

Figure 3. The Thon au chocolat blanc et piment Thaï dish served at Denis Martin's namesake restaurant in Vevey, Switzerland (http://www.denismartin.ch/; Martin, 2007). A dish to be consumed in a single mouthful, thereby delivering a distinctive series of flavour experiences, extended over time to the attentive diner. (The dish itself contains raw tuna, white chocolate, raw Thai chili, toasted peanut oil, wasabi, and a pinch of fleur de sel; see Martin, 2007, pp. 82$83)$.

[Picture from https://www.google.co.uk/search?hl=en\&site=imghp\&tbm=isch\&source=hp\&biw=1348\&bih $=634 \& \mathrm{q}=$ Thon $+\mathrm{au}+$ chocolat + blanc+et + piment + Tha\%C3\%AF\&oq=Thon + au + chocolat + blan c+et+piment+Tha\%C3\%AF\&gs_l=img.3 ..1361.1361.0.2133.1.1.0.0.0.0.87.87.1.1.0...0...1ac .1.64.img..0.0.0.k6BJcpgb7ow\#imgrc=nE0lVJkj3QD8OM\%3A.]

Figure 4. TDS plot highlighting the complex temporal evolution of different elements of the flavour of a singe mouthful of Manos Negras Pinot Noir 2014 (a red wine) held in the mouth 
for 45 seconds. Researchers have recently started to use music (aka 'sonic seasoning'; see Spence, 2017b) in order to try to draw a taster's attention to a certain component in their tasting experience. The suggestion here being that attention is drawn exogenously to elements of the tasting experience based on the crossmodal correspondences. [Figure from Wang, Mesz, \& Spence, (2017).] 
Figure 1.

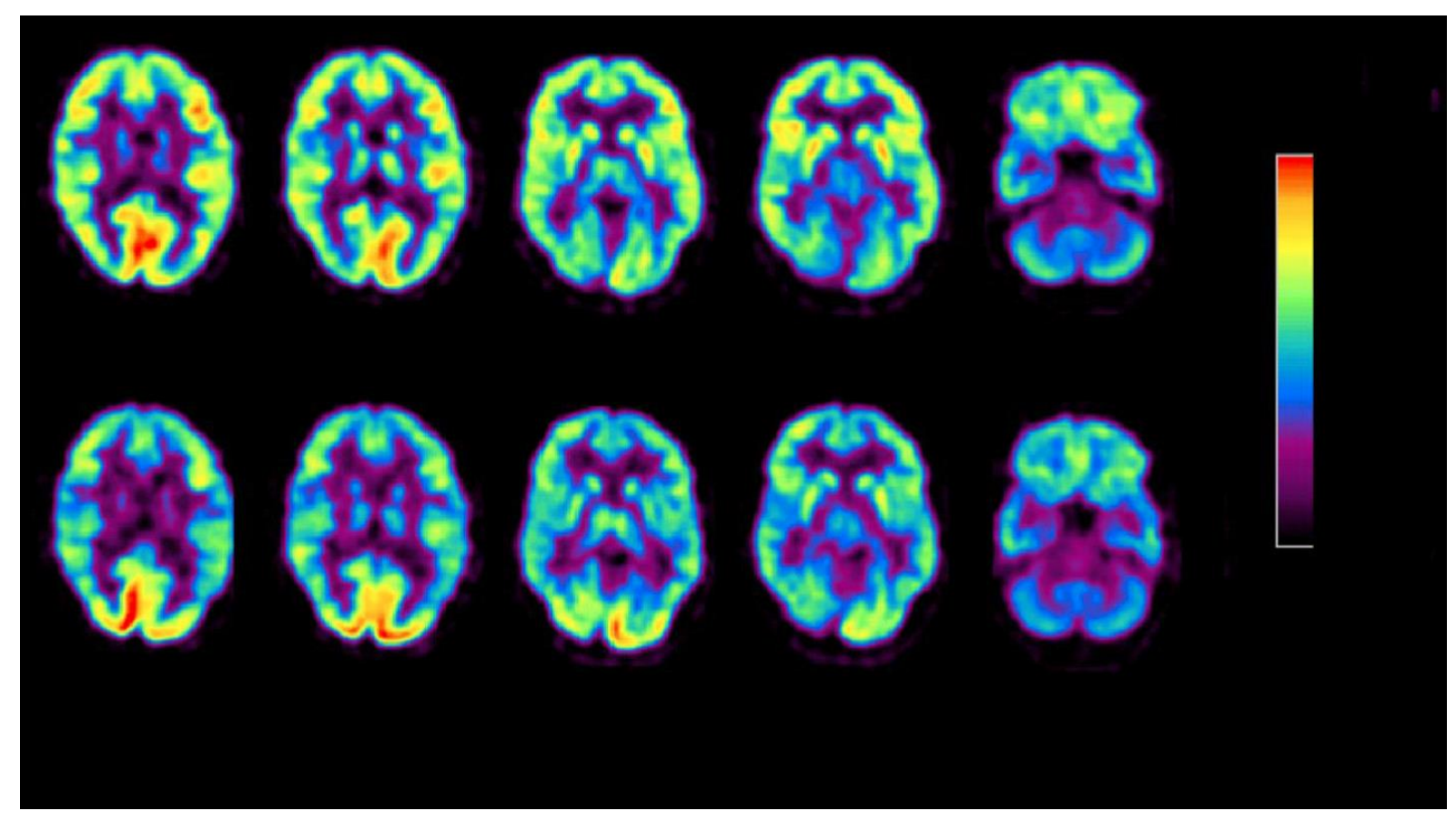


Figure 2.

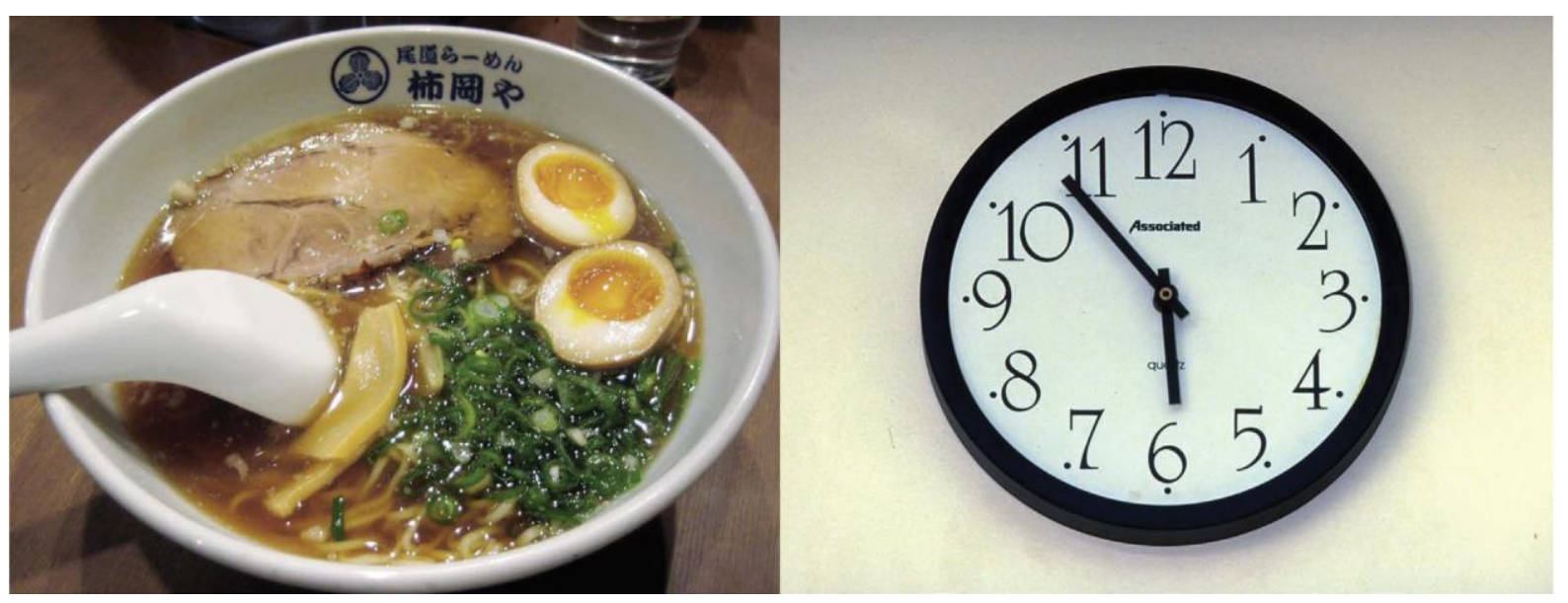


Figure 3.

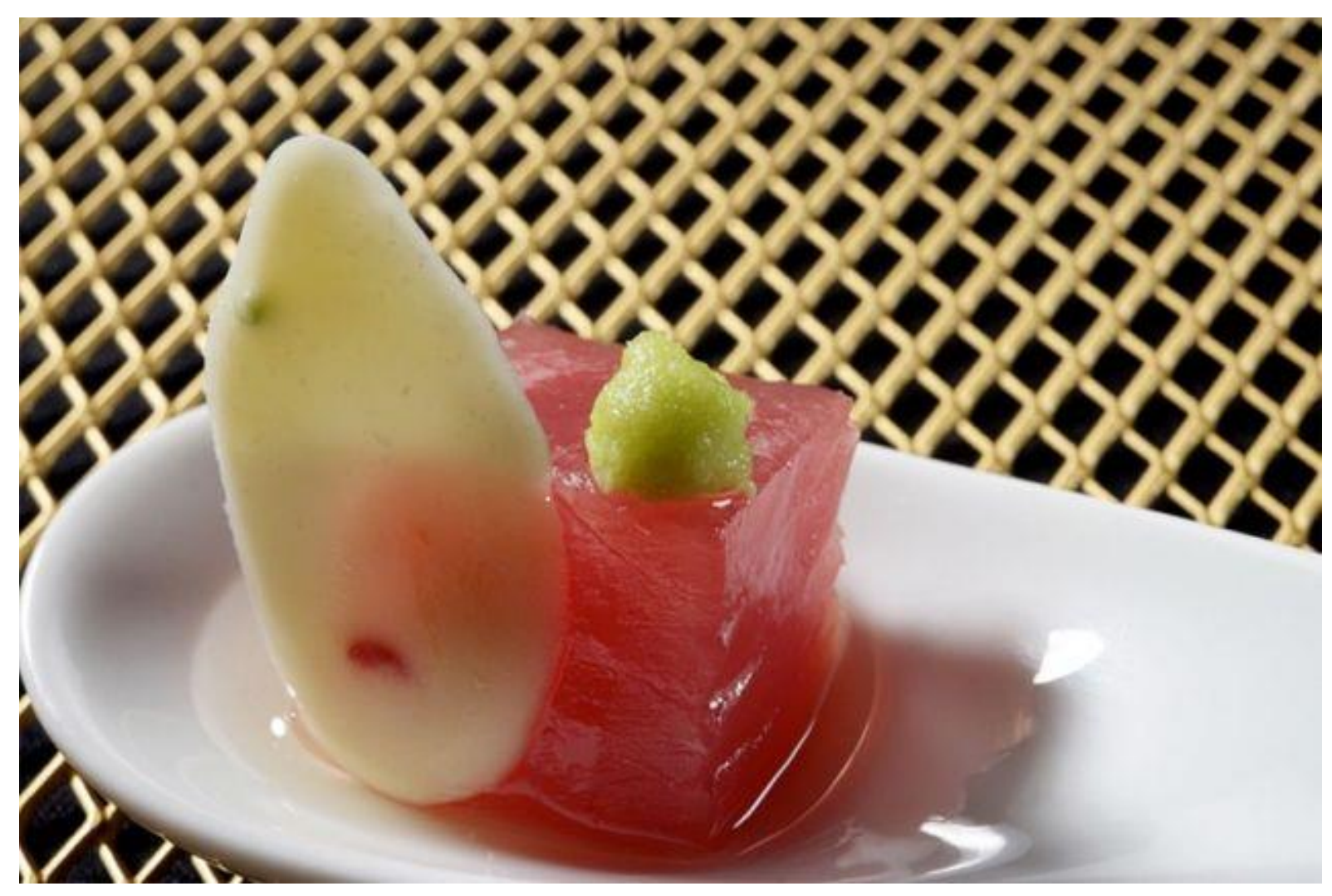


Figure 4.

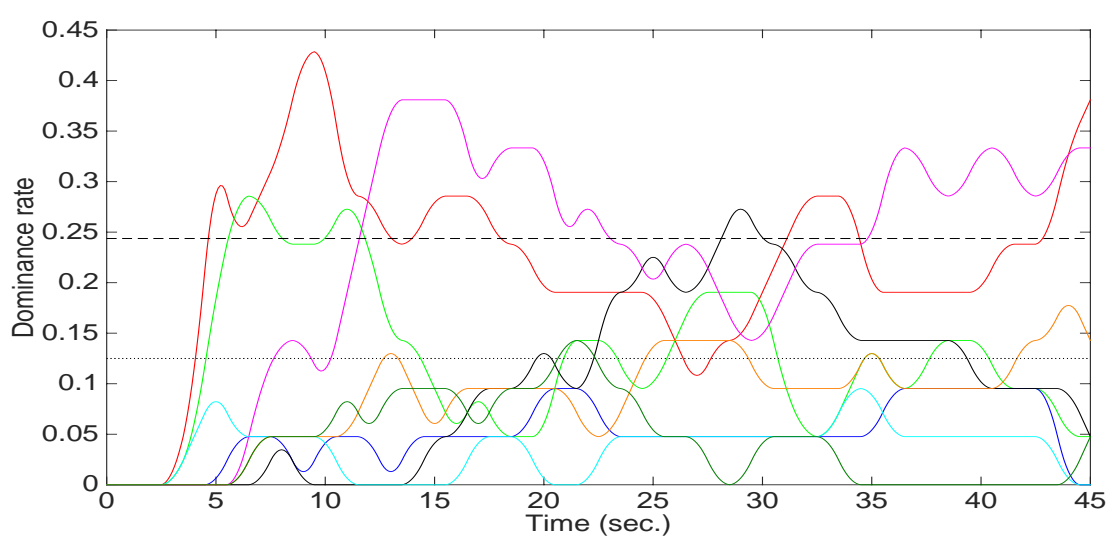

Acid

Alcohol

Woody

- Bitter

Astringent

Sweet

Spicy

Red fruit

Chance

- Sig. Level 